\title{
Pathology of Chronic Rheumatic Mitral Valvulitis in Iran and Its Surgical Implications
}

\author{
Iraj H. NAzARIAN, M.D., F.G.A.P. \\ and Iraj Aryanpur, M.D., F.A.C.C.
}

\section{Summary}

Sixty-two consecutive surgically removed chronic rheumatic mitral valves were classified and tabulated according to their pathological features in relation to age and sex of the patients. The pathological features of the valves are quite different from the cases seen in Western hemisphere. Three types of gross pathological features are described.

First is fibrous stenotic type which has very thick cusps and extremely short chordae tendineae. It is the most frequent rheumatic vavle seen in children, and majority of the valves show pure stenosis, for which probably open commissurotomy is the procedure of choice. Those which have a combination of stenosis and insufficiency usually require valve replacement.

The second is the elastic insufficient type, which has a unique gross pathological feature, consisting of a remarkable elasticity and moderately thickened cusps. A valve replacement or valve repair when feasible is the treatment of choice for this type.

The third is the calcific stenotic type. In this type the cusps are moderately thickened, with short chordae tendineae with various degrees of calcification. This type is seen usually in the 4th decades of life and is more frequent in males. This type of valve must be treated either by open commissurotomy in order to eliminate the risk of embolization of calcific material or with valve replacement.

\section{Additional Indexing Words :}

Rheumatic fever Open commissurotomy Closed commissurotomy Mitral stenosis Mitral regurgitation Mitral valve replacement

\footnotetext{
$\mathrm{O}$
} UR clinical and pathological experience with rheumatic heart disease which represents a random selection from all areas of Iran indicates an accelerated and malignant course as well as a peculiar type of valve pathology, markedly different from the reports of the Western world.1-4) Early appearance of extremely advanced pathology is one of the characteristics of the

From the Departements of Pathology and Pediatric Cardiology, Queen Pahlavi Foundation Cardiovascular Medical Center, Teheran, Iran.

Reprint requests: Iraj Nazarian, M. D., Queen Pahlavi Cardiovascular Center, Shemiran, PO Box 33-423, Teheran, Iran.

Received for publication June 3, 1977. 
disease in our area, similar observations have been reported from other spots in this area..$^{514}$ ) This indicates that for some unknown reasons rheumatic heart disease takes an extremely rapid course in our area.

The purpose of this communication is to discuss the pathological features of rheumatic mitral valve disease in Iran, in order to elucidate its pattern, in respect of the surgical treatment.

\section{Material and Method}

Sixty-two consecutive surgically removed mitral valves were studied. In $71 \%$ of cases (44 of 62) a past history of rheumatic fever was present, but in all cases the gross and microscopic pathological findings were those of rheumatic valvulitis. The age and sex distribution of patients are tubulated (Table I). On gross examination the following pathological features were evaluated:

1. Degree of cusp thickness, in millimeters (Table II).

2. Degree of elasticity of the valve (Table III).

3. Presence of calcific vegetation, ulceration and degree of calcification in respect of age and sex of the patients (Table IV and V).

4. Degree of shortening of chordae tendineae (Table VI).

5. Presence of adhesions of chordae tendineae (Table VII).

Table I. 62 Consecutive Specimens of Rheumatic Mitral Valve Disease, Age and Sex Distribution

\begin{tabular}{c|c|c}
\hline \multirow{2}{*}{ Age in years } & \multicolumn{2}{|c}{ No. of patients } \\
\cline { 2 - 3 } & Male & Female \\
\hline $10-15$ & 3 & 5 \\
$16-20$ & 7 & 7 \\
$21-25$ & 4 & 4 \\
$26-30$ & 2 & 2 \\
$31-35$ & 4 & 7 \\
$36-40$ & 3 & 5 \\
$41-45$ & 3 & 2 \\
$46-49$ & 2 & 2 \\
\hline Total & 28 & 34
\end{tabular}

Table II. Pathologic Types and Degree of Cusps Thickness

\begin{tabular}{l|c|c|c}
\hline \multicolumn{1}{c|}{ Types } & Thickness in millimeters & No. of valve & $\%$ \\
\hline A. Fibrous stenotic valves & $4-10$ & 16 & 26 \\
B. Elastic insufficient valves & $1-3$ & 21 & 34 \\
C. Calcific stenotic valve & $3-4$ & 25 & 40
\end{tabular}


Table III. Degree of Elasticity in Comparison to Normal Valve

\begin{tabular}{l|c|c|c}
\hline Degree of elasticity & Pathological type & No. of valve & $\%$ \\
\hline Reduced & Type A (fibrous stenotic valve) & 16 & 26 \\
Increased & B (elastic insufficient valve) & 21 & 34 \\
Unchanged or reduced & " C (calcific stenotic valve) & 25 & 40
\end{tabular}

Table IV. Degree of Calcification in 62 Specimens

\begin{tabular}{l|c|c}
\hline \multicolumn{1}{c|}{ Calcification } & No. of valve & $\%$ \\
\hline No calcification (Types A and B) & 40 & 65 \\
Vegetative and ulcerative (focal) & 15 & 24 \\
Marked (diffuse) & 7 & 11
\end{tabular}

Table V. Mitral Valve Calcification with Consideration of Age and Sex

\begin{tabular}{c|c|c}
\hline Age in years & Male & Female \\
\hline $0-9.9$ & 0 & 0 \\
$10-19.9$ & 1 & 1 \\
$20-29.9$ & 2 & 2 \\
$30-49$ & 9 & 6
\end{tabular}

Table VI. Extreme Shortening of Chordae Tendineae (Qualitative Assessment)

\begin{tabular}{c|c|c}
\hline Shortening of chordae & No. of valves & Percent \\
\hline Type A (fibrous stenotic valve) & $\frac{14}{16}$ & 88 \\
B (elastic insufficient valve) & $\frac{5}{21}$ & 24 \\
C (calcific stenotic valve) & $\frac{9}{25}$ & 36
\end{tabular}

Table VII. Adhesion of Chordae Tendineae, Age and Sex Distribution

\begin{tabular}{l|c|c}
\hline & Age & No. of patients \\
\hline \multirow{3}{*}{18 Females } & $10-15$ & 4 \\
& $16-20$ & 6 \\
$21-25$ & 3 \\
\hline \multirow{3}{*}{10 Males } & $>25$ & 5 \\
& $10-15$ & 1 \\
& $16-20$ & 4 \\
& $21-25$ & 0 \\
\end{tabular}




\section{Pathologic Features of the Mitral Valve}

The pathology of the mitral valve, which had the characteristic gross and histological features of rheumatic valvulitis, is classified into 3 types:

A. Fibrous stenotic valves (Fig. 1):

Fibrous stenotic valve is the most common type (6 of 8) in children below 15 years of age and less common above that age (10 of 54), without significant sex difference. On gross examination, the valve commissures are completely fused, the cusps are extremely thickened up to $10 \mathrm{~mm}$, and have an extremely hard consistency, the posterior mitral leaflet is usually $(71 \%)$ thicker than the anterior leaflet. The valve orifice is markedly stenotic and has a "fish-mouth" appearance. Thick ening, fusion, absorption and shortening of chordae tendineae are so severe that the papillary muscles are often in opposition to the valve margins. Fibrous tissue adhesions extending from the valve leaflet to the ventricular wall obliterate the angle between the leaflets and the wall. At times in the older adolescents small calcified freckles may be observed on the free edge of the cusps. Clinically these valves produce pure stenosis or combined stenosis and regurgitation. Microscopically, the cusps show a homogenous hyalinized and fibrocollagenized tissue (Fig. 2). Lymphocytes and other inflammatory cells which are present during healing stage (Fig. 3) tend to disappear. The tricuspid valve shows active inflammation more commonly than the mitral valve. In pediatric age group, unlike adults, stenotic lesions in the tricuspid valve are hardly ever seen.

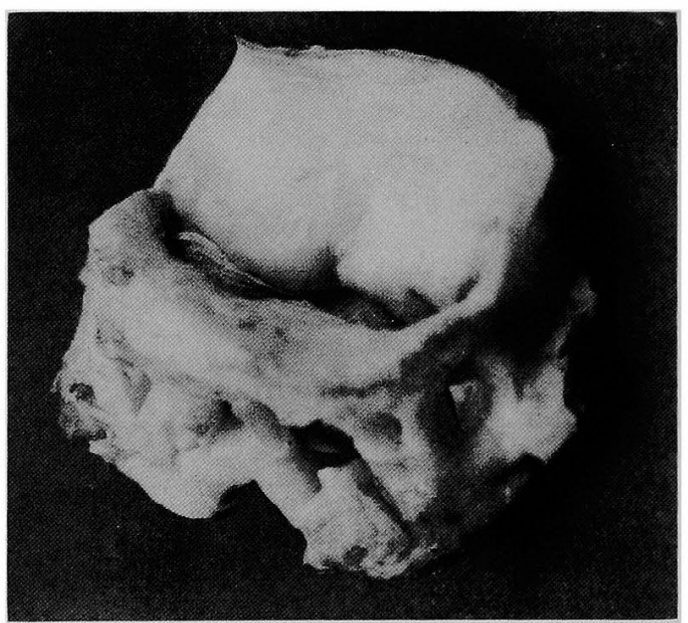

Fig. 1. Type A, fibrous stenotic mitral valve. Note the extreme thickening of the leaflets, fusion of the commissures and absorption of the extremely thickened and shortened chordeae tendineae to the cusp. There is no evidence of calcification in the specimen. 
Vol. 19

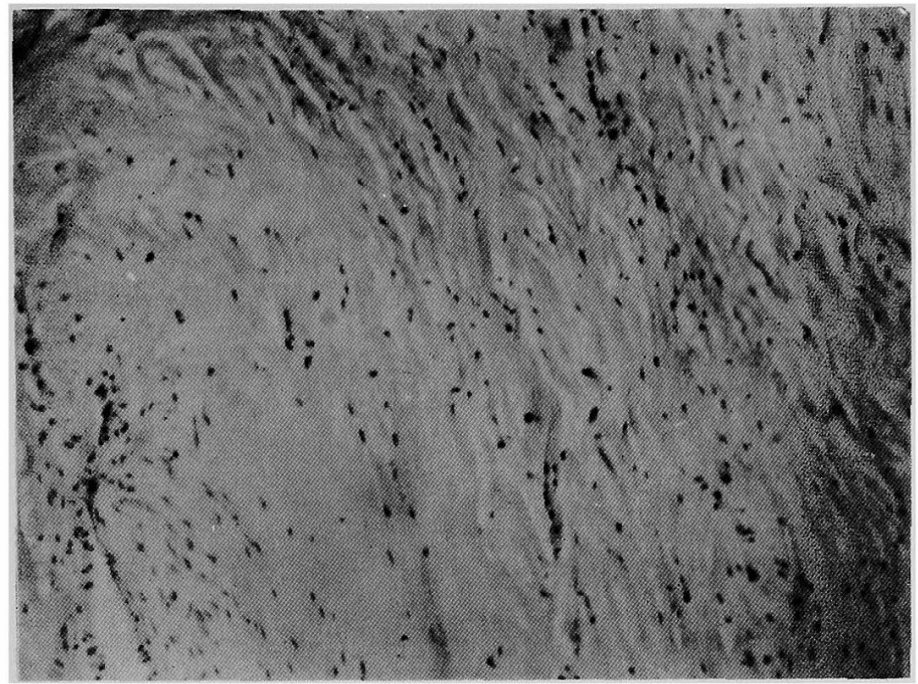

Fig. 2. Histological appearance of a healed rheumatic mitral valvulitis. Section of a cusp shows complete fibrosis and collagenization (Hematoxylin and Eosin stain $\times 100$ ).

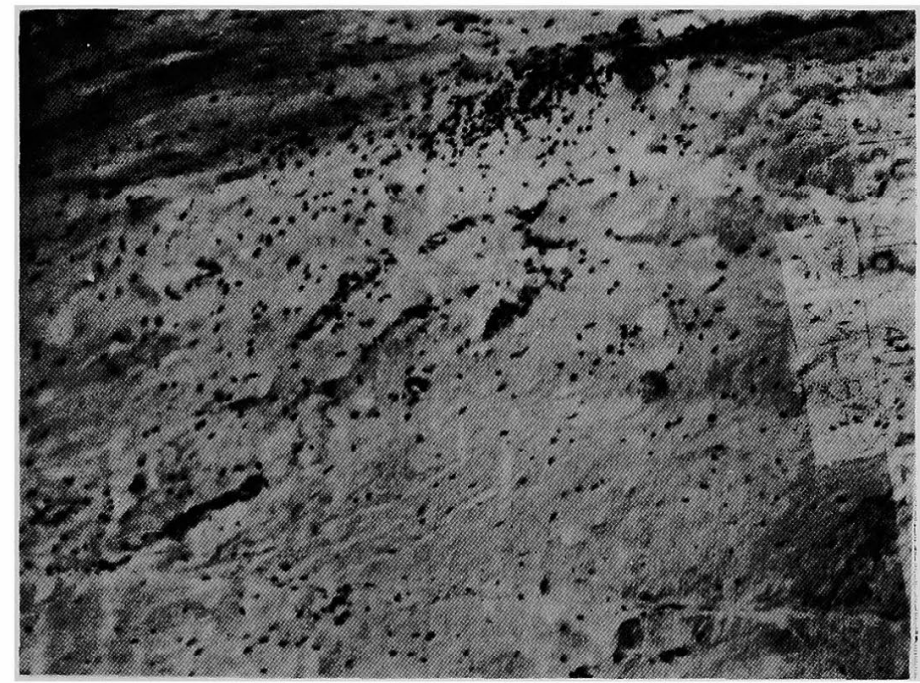

Fig. 3. Histological demonstration of a healing rheumatic mitral valvulitis. Perivascular lymphocytic and mononuclear cell infiltration is evident (Hematoxylin and Eosin stain $\times 100$ ).

B. Elastic insufficient valves (Fig. 4):

These valves are less commonly seen in pediatric age group ( 2 of 8 ), and more commonly present in cases above 15 year of age (19 of 54). The valve leaflets are fused and thickened from 1-3 mm, with smooth and glistening atrial and ventricular surfaces. The most striking feature of this type of valve is the presence of 
extreme elasticity (Fig. 5), retraction and curling of the leaflets associated with high degrees of elasticity, leading to predominant mitral regurgitation with practically no stenosis. The chordae tendineae are short and slightly thickened with minimal fusion. Calcification is not usually present. Microscopic examination of the leaflets shows a dominance of homogenous fibroelastic tissue. Elastic stains demonstrate rows of elastic fibers (Fig. 6).

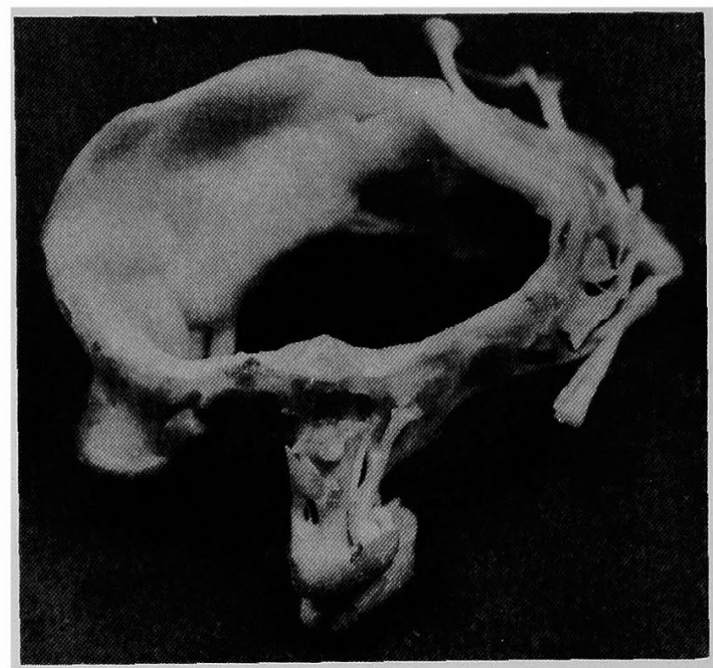

Fig. 4. Type B, elastic regurgitant mitral valve. Note the dilated orifice. The cusps are slightly thickened. The commissures are fused, the chordeae tendineae although shortened, lack fusion and absorption to the cusps. There is no evidence of calcification in this type of mitral valve.

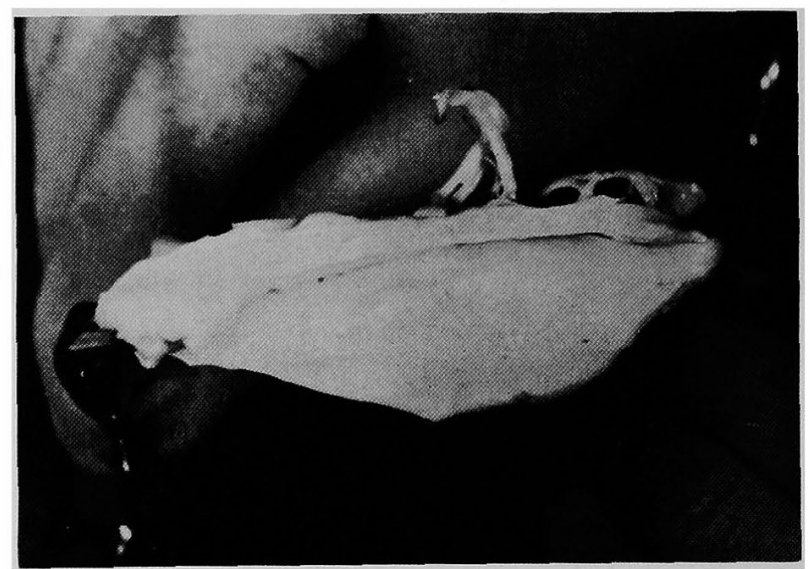

Fig. 5. Type B, elastic insufficient valve, demonstration of elasticity by stretching the valve from its both commissural sides. Note conversion of the insufficient lumen to an elongated slit. 


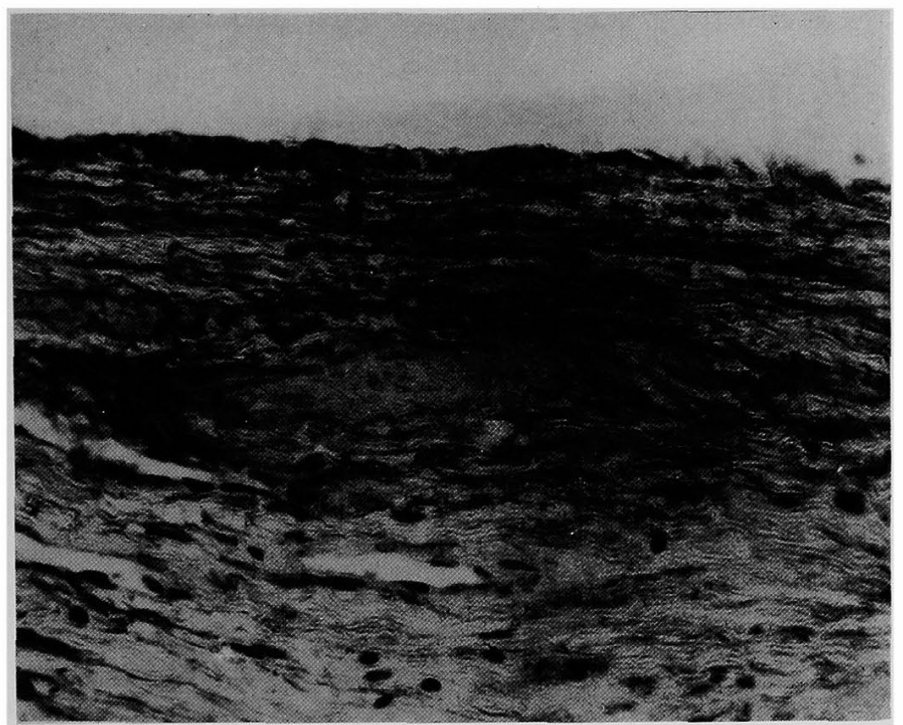

Fig. 6. Histological appearance of a cusp in Type B elastic insufficient valve, showing abundance of elongated elastic fibers in a fibrotic background (Elastica Van Gieson $\times 100)$.

C. Calcific, stenotic valves (Fig. 7):

Such valves were not encountered in children below 15 years of age ( 0 of 8 ), and are almost exclusively seen in the adult age (25 of 54). Such valves have lesser thickening of the cusps and a lesser degree of shortening of the chordae tendineae

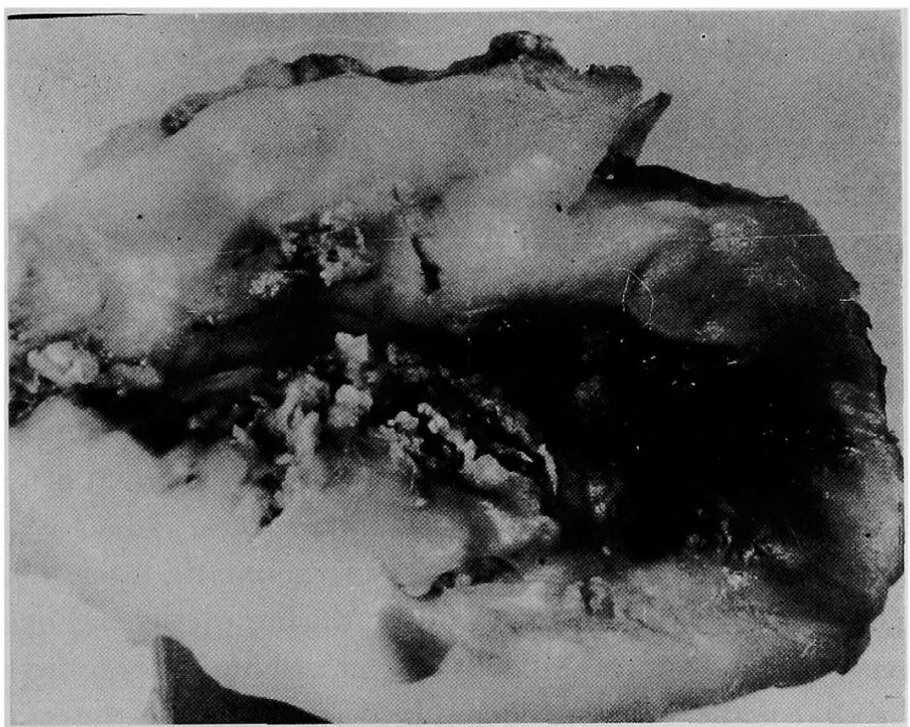

Fig. 7. Type G, calcific stenotic mitral valve, showing gross fibrous thickening and distortion of cusps with calcium ulcerating through the adherent commissures. 


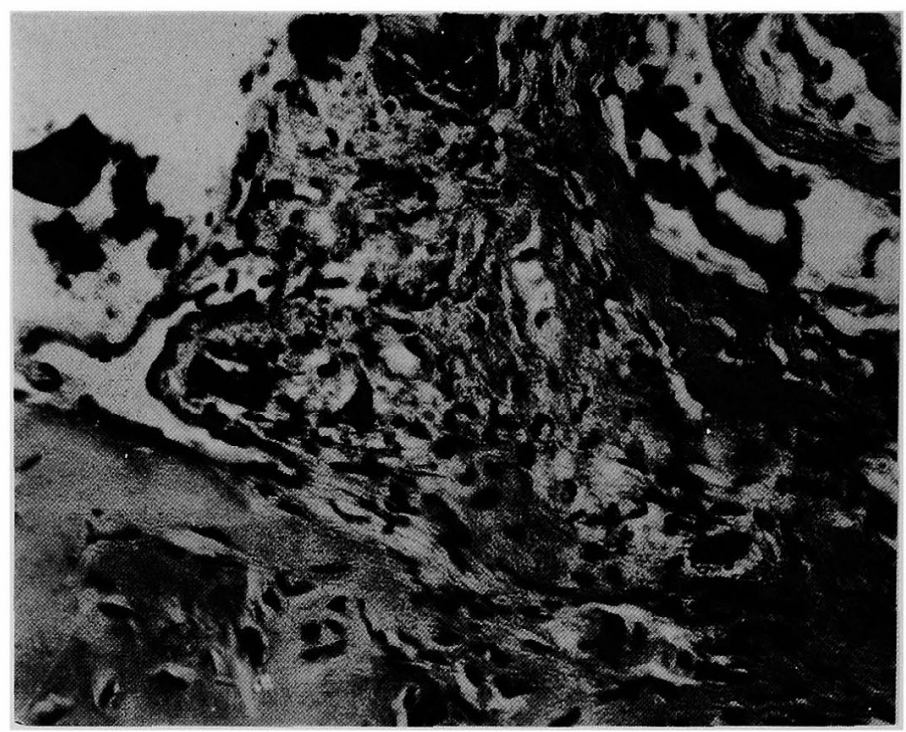

Fig. 8. The inflammatory reaction surrounding the clacified foci includes giant cells and pallisaded fibroblasts (Hematoxylin and Eosin $\times 240$ ).

than fibrostenotic valves. The cusps are not as stiff as in Type $\mathrm{A}$ and show more flexibility. The mitral orifice is stenotic in $62 \%$ of this type or shows a combination of stenosis and regurgitation $(38 \%)$. Areas of focal calcification $(62 \%)$ or diffuse calcification $(38 \%)$ are observed on the cusps and may appear as calcified ulcers or vegetations. Microscopically there are calcified areas trapped in a fibrocollagenized background and occasionally a mononuclear cell reaction is seen around the calcified areas (Fig. 8).

\section{Discussion}

Based on our clinical experience ${ }^{1)-3)}$ the high frequency of rheumatic mitral valve disease especially mitral stenosis with or without regurgitation, in young children, suggests that mitral stenosis develops rapidly following an attack of rheumatic fever. While it has been claimed that a period of at least 10 years after an acute attack of rheumatic fever is required for mitral stenosis to develop, ${ }^{15}$ ) our observations suggest that rheumatic heart disease takes a rapid course in the pediatric population in Iran. In an average period of less than 5 years after a primary attack of rheumatic fever mitral stenosis develops and often leads to serious disability during the second decade of life. Similar observations have been made in our neighbouring countries. ${ }^{5)-7), 11)-14)}$ It is possible that many patients with mitral regurgitation during first attack of acute rheumatic fever make a full recovery; however, in children with chronic rheumatic heart disease, the frequent occurrence of mitral valve stenotic 
lesions and the relatively less common incidence of pure mitral regurgitation indicate rapid progression of the disease from insufficiency to stenosis. Most of our patients with rheumatic mitral valve disease were females $(55 \%)$. In this study none of the patients were more than 49 years old. In patients with a past history of rheumatic fever, the lesion can be attributed to rheumatic fever with confidence, as was the case in $71 \%$ of our patients, but even in the absence of past history for rheumatic fever the large number of cases of mitral stenosis or insufficiency can statistically exclude congenital etiology, particularly in children with a negative past history, since rheumatic etiology of cases reported herein has been invariably verified, both by gross and microscopic study of the valves. We believe that the high incidence and the extremely advanced lesions are due to inadequate early recognition and treatment of streptococcal disease, and lack of secondary prophylaxis, nevertheless a racial factor may play a role. A recent survey of throat cultures in Iranian children has shown that $57 \%$ of $\beta$-hemolytic streptococci isoloted were $\mathrm{M}$ typeable. ${ }^{16)}$ This may be a clue to the possibility of high virulence and rheumatogenicity of streptococci in our area. The pathological examination of chronic rheumatic mitral valve in this study indicates 3 different gross patterns. Type A(fibrous stenotic type) occurred in $26 \%$ of the surgical specimens. In this type the mitral valve is very thick measuring between $4-10 \mathrm{~mm}$. Their chordae tendineae are extremely short and are adherent to one another. These valves have been removed because of presence of both stenosis and insufficiency. In purely stenotic mitral valves of Type A the most effective surgical treatment is open commissurotomy. This is in contrast to the report from our area that considers closed mitral commissurotomy as the operation of choice." We believe that closed commissurotomy is often effective, but under ideal circumstances open procedure is probably superior. At times during open heart surgery the dilator can easily open the valve up to $3.5-4 \mathrm{~cm}$ in diameter, but as soon as the dilator is removed, the valve orifice returns to its original size. ${ }^{4}$

The true incidence of Type A stenotic mitral valves is not reflected in this report, simply because they were not removed surgically. In our clinical experience a half of mitral valve operations are either open or closed commissurotomies.

Type $B$ (elastic insufficient type) of rheumtic mitral valve, comprised approximately $34 \%$ of the mitral valves studied. Fifty-six $\%$ of these patients were young females. The chordae tendineae are minimally shortened. This type of valve often has the appearance of a floppy valve with wide, thin and prolapsed cusps. Except for histological examination, it lacks softening and myxomatous changes of fibrosa which is seen in floppy valve and it is com- 
posed of fibroelastic tissue compatible with chronic rheumatic valve changes. Valve replacement is required, since the elasticity of the valve may render it unsuitable for valvuloplasty and recurrent insufficiency is common, nevertheless we think that in a selected group of patients plastic mitral valve repair may be an ideal operation.

Type C(calcific stenotic type) which occurred in $40 \%$ of the specimens, is more commonly seen in male patients $(58 \%)$ and is usually seen in patients over 30 years of age. In this category the cusps are thickened and chordae tendineae are moderately shortened. Most of the cusps have a minimal amount of elasticity, except in the diffusely calcified valves where the elasticity is completely absent. Although the majority of the submitted valves may have a small focus of calcification, diffuse calcification with involvement of valve ring was only noted in $11 \%$ of the valves in this study. These valves may either present with pure stenosis or combination of stenosis and insufficiency. In any case these valves must be treated with open heart surgery, in order to have a direct vision for prevention of calcific embolization. In cases of pure stenosis an open commissurotomy may suffice, but in those with combined regurgitation and stenosis particularly in the face of diffuse calcification, valve replacement becomes necessary.

\section{ConcLusion}

This pathological study of the chronic mitral valvulitis reveals the following features:

1. Histopathological study of the valves shows that the normal anatomy of the cusp is replaced by fibrosis, collagenization, and calcification of the cusp substance. Diffuse calcification is rare.

2. In 28 out of 62 cases the chordae tendineae are extremely short and adherent to one another. In some examples the chordae are completely absorbed to the cusps and the papillary muscle is in close contact with cusps.

3. The papillary muscles may become extremely fibrotic in the process of valvulitis and along with valve commissures and chordae tendineae create a high tensile strength.

4. Elastic insufficient valve which at times appear with prolapse of the cusps is an interesting pathological feature and needs attention in respect to its surgical treatment in our area.

5. High incidence of chronic rheumatic mitral valvulitis in very young children and the relatively less common incidence of pure mitral regurgitation are of interest and indicates a rapid progression of the disease from insufficiency to stenosis, possibly due to accelerated host response and perhaps 
highly potent rheumatogenic streptococci.

\section{References}

1. Aryanpur I: A profile of heart disease in Iranian children. Proceedings of the 5th Asian Pacific Congress of Cardiology, p. 485, Singapore, October 1972

2. Aryanpur I, Nazarian I, Siassi B: Rheumatic heart disease in the developing countries in Heart Disease in Infants, Children and Adolescents, ed Moss AJ, Adams FH, Emmanouilides $G$ (2nd Ed) (in press)

3. Nazarian I: Pathology of rheumatic mitral valves in Iran. Proceeding of the 5th Internaternational Conference in Cardiac Rehabilitation, p. 142, Tehran, November 1974

4. Khonsari S: Surgical aspects of mitral valve disease. Proceedings of the 5 th International Conference in Cardiac Rehabilitation, p. 150, Tehran, November 1974

5. Abdin ZH, Fissa A: Rheumatic fever and rheumatic heart disease below the age of five years in Tropices. Ann Rheum Dis 24: 389, 1965

6. Al-Bahrami LR, Thamer MA, Al-Omeri $\mathbf{M}$ et al: Rheumatic heart disease in the young in Iraq. Brit Heart J 28: 824, 1966

7. Bhayana JN, Khanna SK, Gujita SR et al: Mitral stenosis in the young in developing countries. J Thorac Cardiovasc Surg 68: 127, 1974

8. DeSilva S: Incidence of rheumatic fever in Ceylon. Arch Dis Child 34: 247, 1959

9. Gharib R: Actue rheumatic fever in Shiraz, Iran. Prevalence and characteristics in two socio-economic groups. Am J Dis Child 118: 694, 1969

10. Joorabchi B: Rheumatic heart disease in school children in Shiraz. Proceedings of the VII Middle-Eastern-Mediterranean Pediatric Congress, p. 5, Tehran, September 1969

11. Roy SB, Bhatia $\mathrm{ML}_{3}$ Lazaro EJ, Ramalingswami V: Juvenile mitral stenosis in India. Lancet 2: 1193, 1963

12. Tahernia AG, Motamed F, Sharif $H$ : Some clinical observations on rheumatic fever in childhood. Clin Padiat 10: 530, 1971

13. Padmavati S: Epidemiology of cardiovascular disease in India. I. Rheumatic heart disease. Circulation 25: 703, 1963

14. Reale A, Collella G, Bruno AM: Mitral stenosis in childhood. Clinical and therapeutic aspects. Am Heart J 66: 15, 1963

15. Selzer A, Keith C: Natural history of mitral stenosis. A review. Circulation 45: 878, 1972

16. Gharagozloo R, Jamshidi MS, Ghadimi H: Microbiological and epidemiological study of streptococcal sore throat at a children's clinic. A one year study. Pahlavi Med J 7: 334, 1976

17. Reed GE, Kloth $\mathbf{H H}$, Kelly B et al: Long term results of mitral annuloplasty in children with rheumatic mitral regurgitation. Circulation 49 (suppl): 11-189, 1974

18. Levy MJ, Vidne B: Rheumatic valve disease in childhood and adolescence. Surgical treatment. Chest 63: 933, 1973

19. Gotsman MS, Van der Horst RL: Surgical management of severe mitral valve disease in childhood. Am Heart J 90: 685, 1975 